\title{
Is Absence of Spontaneous Agglutinates of Spermatozoa in Semen a Reliable Indicator of Non-Autosensization against Human Sperm Antigens?
}

\author{
Antoine Laudat*, Laurence Burc-Struxiano \\ Laboratoire de Biologie Médicale, Unité de Biologie de la Reproduction et d’Assistance Médicale à la Procréation Hôpital Louis Pasteur 4, \\ Le Coudray, France \\ Email: *alaudat@ch-chartres.fr, lburc@ch-chartres.fr
}

How to cite this paper: Laudat, A. and Burc-Struxiano, L. (2016) Is Absence of Spontaneous Agglutinates of Spermatozoa in Semen a Reliable Indicator of NonAutosensization against Human Sperm Antigens? Open Access Library Journal, 3: e2978.

http://dx.doi.org/10.4236/oalib.1102978

Received: September22, 2016

Accepted: November 4, 2016

Published: November 7, 2016

Copyright $\odot 2016$ by authors and Open Access Library Inc.

This work is licensed under the Creative

Commons Attribution International

License (CC BY 4.0).

http://creativecommons.org/licenses/by/4.0/

(c) (i) Open Access

\section{Abstract}

Objective: Here we compared the results of a prospective study systematically screening for antisperm antibodies in a cohort of subfertile males to the results of a previous retrospective study in equally subfertile patients where screening for antisperm antibodies was performed solely if semen presented spontaneous agglutinates of sperm. Methods: The prospective study was conducted on 317 semen analyses between 1 September 2014 and 9 December 2015 and the retrospective study investigated 2823 semen analyses performed between 1 April 2004 and 31 March 2014. Sperm parameter analysis used exactly the same techniques across patients in both studies. Screening for IgG and IgA class antisperm antibodies was performed by using the direct (in-semen) MAR test with immunobeads. Results: Retrospectively, 76 $(2.69 \%)$ of the 2823 patients in the cohort had a positive MAR test after presenting semen showing sperm agglutination. Compared to this group, the prospective study found a significantly higher number of patients presenting antisperm antibodies (positive MAR test in 25 patients, i.e. $7.88 \%$ ). Of these 25 patients, IgA and mixed (IgG and $\operatorname{IgA}$ ) class antisperm antibodies were significantly higher in the prospective group than those in the retrospective group. Conclusion: Given how antisperm antibodies can damagingly block or hamper different prefertilization and possibly postfertilization events, screening for antisperm antibodies solely on the basis of sperm agglutinates does not look adequate. This study advocates making screening for autoimmunity to sperm a routine part of the basic workup for male subfertility.

\section{Subject Areas}

Biochemistry, Cell Biology 


\section{Keywords}

Antibodies, Antigens, Fertility, Sperm

\section{Introduction}

It was over a century ago, back in 1899, that Landsteiner and Metchnikoff, in two independent studies, first described how human spermatozoa were highly antigenic. The upshot to this demonstration of antigenicity is the risk that males may, in some cases, go on to develop autoimmunity to sperm. Science had to wait another half-century until 1954 before demonstrating the presence of antisperm antibodies as a cause of certain cases of male and/or female subfertility by another two independent teams [1] [2]. Several hypotheses have been put forward to explain how human males can mount an autoimmune response to sperm. A breach of the blood-testis barrier, a physical barrier between the seminiferous tubules and the bloodstream, is likely at least partly responsible for triggering such disease. This would explain why autoimmunity to sperm is very often observed in cases of congenital defects leading to obstruction of the genitourinary tract (congenital bilateral absence of the vas deferens) or as a result of vasectomy, trauma, repeat infection, testicular inflammation, sexual practices, and many other factors. Note that not just men but women also have a complex physiological system of barriers separating spermatozoa-seen as "foreign" invader cells-from the immune system. If these barriers are breached, then the female body will produce iso-antibodies with similar effects on fertility to male antisperm antibodies [3] [4].

Antisperm antibodies have many well-identified effects on fertility. Antisperm antibodies are immunoglobulins which diminish the mobility and progressive motility of spermatozoa by agglutinating or immobilizing it inside the semen and/or female genital system. They can also alter sperm capacitation and the sequence of steps leading into the acrosome reaction, and even block sperm-oocyte interaction by altering the binding to the zonapellucida. There is also good evidence that these compounds, which occur as IgG, IgA and/or IgM, cause alterations in early stages of embryonic development by blocking cleavage events [4] [5] [6].

It is unfortunately fairly rare for a laboratory to have full documented history on a given patient's subfertility and thus clues to a causal factor identifying and labelling their loss of fertility. However, in the absence of one or more identified causes, the first sign pointing to antisperm antibodies available to the semen tester is the demonstration

of fresh spontaneous agglutinates (clumps of live sperm) under the optical microscope [7] [8] [9]. If sperm agglutinates are effectively present, the semen tester may move to screen for antisperm antibodies by direct immunoglobulin assay using the immunobead technique.

The aim of this study was to assess the reliability of the relationship connecting the presence of sperm agglutinates to the occurrence of antisperm autoimmunity. The approach adopted was to retrospectively review a decade of medical records from 2823 
patients and extract the dataset of patients that had been directly screened for antisperm antibodies solely on the basis of semen presenting spontaneous agglutinates. This dataset was then compared against a dataset from a prospective study, in which $317 \mathrm{pa}-$ tients were systematically screened for antisperm antibodies.

\section{Material and Methods}

\subsection{Retrospective Study}

Between 4/01/2004 and 3/31/2014, semen was collected from 2823 patients (age: 34.10 \pm 6.63 years old, mean \pm standard deviation, minimum: 18 years old, maximum: 70 years old) at our laboratory by masturbation into special sterile plastic cups. Prior sexual abstinence of 3 days ( 2 to 7 days) before sperm collection was recommended (actual sexual abstinence: $3.67 \pm 2.25$ days, minimum: 1 day, maximum: 60 days).

\subsection{Prospective Study}

Between 9/01/2014 and 12/09/2015, semen was collected from 317 patients (age: 34.36 \pm 6.93 years old, minimum: 18 years old, maximum: 61 years old) at our laboratory by masturbation into same-model sterile plastic cups. Prior sexual abstinence of 3 days (2 to 5 days) before sperm collection was recommended (actual sexual abstinence: $4.05 \pm$ 2.04 days, minimum: 2 days, maximum: 25 days).

\subsection{Semen Analysis}

For both studies, semen specimens were kept in an incubator at $37^{\circ} \mathrm{C}$ during analysis. Sperm count was performed in a Neubauer chamber after dilution of semen with distilled water. Thin semen smears were air-dried, fixed with ethanol-ether $(1 / 1, v / v)$, stained with Harris haematoxylin and Shorr's stain (CML-ID, Nemours, France), and mounted. A total of 100 spermatozoa were examined under high magnification (1000x, under oil) using transmitted light differential interference contrast (Nikon Eclipse 80i, Nikon France, Champigny-sur-Marne, France) and classified according to David et al. [10]. This method distinguishes normal cells, and here at our laboratory we also distinguised seven head abnormalities (tapered, thin, thin basis, microcephalous, macrocephalous, acrosome anomalies, and double), three midpiece abnormalities (cytoplasm droplet, bent tail, absent), and six tail abnormalities (absent, short, coiled, multiple, thick, irregular diameter). Using a multiple entry system, all abnormalities of each sperm cell were recorded to ensure no one abnormality was underestimated in relation to another. At the end of the process, a multiple anomalies index (MAI) was calculated as follows: mean number of anomalies per abnormal sperm.

One hour after ejaculation, vitality was assessed on thin semen smears stained with eosin Y 0.67\% (RAL, Paris, France) and nigrosin 5\% (Prolabo, Paris, France) (1/1, v/v). At the same time, motility (quality of sperm progression) was scored as IM (complete immotility, no movement), NP (non-progressive motility), and PR (progressive motility, which is the sum of a good and an average motility). Spontaneous agglutinates are defined as a cluster of alive spermatozoa. All sperm analyses were performed by a staff 
of authorized biologists as per standard World Health Organization procedures 1999 and 2010 [11] [12].

\subsection{Direct Immunobeads Test for the Detection of Sperm Antibodies (Mixed Antiglobulin Reaction Test, Direct Sperm MAR Test)}

Briefly, $10 \mu \mathrm{L}$ of fresh untreated sperm was mounted on a slide and mixed with $10 \mu \mathrm{L}$ of sperm MAR IgG latex particles and $10 \mu \mathrm{L}$ of sperm MAR IgG antiserum (FertiPro, Beernem, Belgium), and then coverslipped. The result was red after 2 and 10 minutes under a phase-contrast microscope at 400× magnification (Olympus BX40, Olympus France, Rungis, France). Results were expressed as percentage of motile sperm bound to latex particles. For the sperm IgA MAR test, $10 \mu \mathrm{L}$ of fresh untreated sperm was mixed with $10 \mu \mathrm{L}$ of sperm IgA MAR latex particles (FertiPro, Beernem, Belgium) and then as above. The requirements of the sperm parameter criteria required for a direct sperm MAR test evaluation were as follows: PR motility not less than $10 \%$ and sperm count per $\mathrm{mL}$ not less than 300,000. Values $\geq 10 \%$ fixed immunobeads (IgG and/or IgA) were considered positives, as per the supplier's memo.

\subsection{Ethics Committee Approval}

These studies were approved by the Ethics Committee of the hospital Louis Pasteur, Chartres.

\subsection{Quality Assurance Policy}

In our laboratory, the performance of all operators performing reproductive biology analyses is assessed via internal and external quality controls on a number of quality indicators [13]. Moreover, the lab's medical biology unit is accredited to European standard NF EN ISO 15189 for all sperm analyses as well as for the direct sperm MAR test.

\subsection{Statistical Analysis}

Results were expressed as means \pm standard deviation. Differences between the retrospective and prospective patients groups were assessed using the unpaired Student's $t$-test (StatView 4.01, SAS Institute, USA). A probability value $(P)$ of $<0.05$ was considered significant.

\section{Results}

\subsection{Sperm Parameters}

The semen characteristics of the two patient populations are summarized in Table 1.

\subsection{Results of the Direct Sperm MAR Test}

Retrospective analysis on 2823 semen tests showed that 76 patients (2.69\%) presented fresh spontaneous agglutinates. All 76 patients had been direct MAR-tested to screen for antisperm IgG and IgA. The results of these tests read as follows: 40 patients tested IgG-positive (1.41\% of the total population, $52.63 \%$ of the positive MAR test popula- 
Table 1. Semen characteristics of the retrospective group $(N=2823)$ and the prospective group $(N=317)$.

\begin{tabular}{ccccc}
\hline \multirow{2}{*}{ Parameters } & \multicolumn{2}{c}{ Retrospective group } & \multicolumn{2}{c}{ Prospective group } \\
\cline { 2 - 5 } & Mean \pm S.D. & Range & Mean \pm S.D. & Range \\
\hline Semen volume (mL) & $3.9 \pm 1.6$ & $0.4-20.0$ & $3.8 \pm 1.5$ & $1.0-10.0$ \\
pH & $7.7 \pm 0.3$ & $6.0-9.0$ & $7.8 \pm 0.4$ & $7.5-9.0$ \\
Spermatozoa per mL & $75.95 \pm 73.88 \times 10^{6}$ & $0.30-903.72 \times 10^{6}$ & $71.58 \pm 65.57 \times 10^{6}$ & $0.32-424.32 \times 10^{6}$ \\
Total spermatozoa & $277.92 \pm 286.29 \times 10^{6}$ & $0.72-3569.18 \times 10^{6}$ & $275.88 \pm 357.57 \times 10^{6}$ & $0.96-4493.68 \times 10^{6}$ \\
Round cells per mL & $2.32 \pm 4.27 \times 10^{6}$ & $0-57.12 \times 10^{6}$ & $2.51 \pm 3.44 \times 10^{6}$ & $0-18.87 \times 10^{6}$ \\
Vitality (\%) & $61.14 \pm 11.64$ & $10-92$ & $64.68 \pm 11.38$ & $20-94$ \\
Progressive & $36.75 \pm 12.49$ & $10-70$ & $39.22 \pm 11.47$ & $10-60$ \\
motility (\%) & & & & $10-50$ \\
Non-progressive & $18.15 \pm 7.77$ & $0-50$ & $15.52 \pm 6.22$ & $20-80$ \\
motility (\%) & $45.09 \pm 11.52$ & $10-90$ & $45.30 \pm 10.68$ & $0-50$ \\
Immotility (\%) & $17.60 \pm 11.83$ & $0-58$ & $17.13 \pm 11.24$ & $1.30-3.30$ \\
Normal forms (\%) & $2.34 \pm 0.44$ & $1.15-3.92$ & $2.10 \pm 0.39$ & \\
MAI & & & &
\end{tabular}

tion), 22 patients tested IgA-positive ( $0.77 \%$ of the total population, $28.94 \%$ of the positive MAR test population) and 14 patients presented a mixed-class IgG plus IgA autoimmunity ( $0.49 \%$ of the total population, $18.42 \%$ of the positive MAR test population). The extreme values for antisperm IgG, IgA and mixed-type antibodies were $10 \%$ $100 \%, 10 \%-40 \%$ and $20 \%-90 \%$, respectively. Our prospective analysis in 317 patients showed that $25(7.88 \%)$ presented fresh spontaneous agglutinates within one hour. These 25 patients were then direct MAR-tested, giving the following results: 7 patients tested IgG-positive (2.20\% of total, $28 \%$ of the positive MAR test population), 12 patients tested IgA-positive (3.78\% of total, $48 \%$ of the positive MAR test population) and 6 patients presented a mixed-class IgG plus IgA autoimmunity (1.89\% of total, $24 \%$ of the positive MAR test population). The two groups were significantly different in terms of incidence rates for MAR-positives, IgA-class antisperm antibody and mixed-class antisperm antibody, all of which were significantly higher in the prospective dataset than the retrospective dataset. Results of the direct sperm MAR tests (IgG and IgA) in the two population datasets are summarized in Table 2.

\section{Discussion}

Spermatozoa are highly specialized reproductive cells that also possess a major antigenic component and so are kept physiologically separated from the bloodstream by the blood-testis barrier [4]. However, various diseases or physical injuries can break this barrier. When the blood-testis barrier is breached, the spermatozoa escape and come in direct contact with lymph or bloodstream immunocompetent cells which mount a response where activated lymphocytes produce antibodies against the antigens expressed 
Table 2. Results of the direct MAR test in the retrospective and prospective groups.

\begin{tabular}{cccccc}
\hline \multirow{2}{*}{ Direct MAR test } & \multicolumn{2}{c}{ Retrospective group } & \multicolumn{2}{c}{ Prospective group } & Independent \\
\cline { 2 - 5 } & $N$ & $\%$ & $N$ & $\%$ & Student's $t$-test \\
\hline Total & 76 & 2.69 & 25 & 7.88 & $P<0.001$ \\
IgG & 40 & 1.41 & 7 & 2.20 & $P=\mathrm{NS}$ \\
IgA & 22 & 0.77 & 12 & 3.78 & $P<0.001$ \\
IgG\& IgA & 14 & 0.49 & 6 & 1.89 & $P<0.01$ \\
\hline
\end{tabular}

NS: non-significant.

at sites on the surface of the sperm. Intensive research over the years has identified a number of causes that can breach tolerance to non-self and ultimately drive immunological subfertility. Many causal factors found to date include: previous urogenital surgery, vasectomy, inflammatory events localized to the genital tract and/or accessory glands, trauma to epipidymis or deferens, congenital obstruction of the vasa deferentia, infection, orchitis, testicular cancer, varicocele, cryptorchidism, testicular torsion, bone marrow disorders, and homosexuality [3] [4] [5] [6] [8] [14]-[19]. There are also publications suggesting that HLA-system antigens like HLA-B7 and HLA-BW35 alleles may be implicated in antisperm autoimmunity [20]. The mechanisms underpinning antisperm autoimmunity are not fully elucidated. However, in cases of antisperm autoimmunity caused by an obstruction, sperm extravasation into the interstitial tissue of the epipidymis and contact with lymph and bloodstream appear to be the startpoint triggers. Note too that macrophage phagocytosis of spermatozoa could result in antigenic compounds becoming absorbed by cell basal membranes from where they are then transferred into blood capillaries [7] [21]. In cases of antisperm autoimmunity caused by testicular anomalies (cryptorchidism, varicocele, torsion, cancer), as the testicular atrophy leads to venostasis and hyperthermia, the damaged tissue may alter its protection to spermatozoa, triggering an immune response and thereby inducing the production of antisperm antibodies [15]. Finally, in cases of antisperm autoimmunity caused by bone marrow disorders, the production of antisperm immunoglobulin antibodies appears to be linked to recurrent genitourinary infections [17]. Incidence rates for immunological subfertility in men vary widely between studies. The literature cites values ranging from under $3 \%$ to over 40\% [3] [4] [6] [18] [19] [22]. This huge range of variability is likely explained by the many different technologies used to diagnose immunological subfertility, the different cut-offs used and/or the different signs prompting a move to screen for antisperm autoimmunity. Antisperm autoimmunity is a lot rarer in women, where reported incidence rates range from $0.2 \%$ to $1.6 \%$ [4]. Human antisperm autoimmunity appears to involve three classes of immunoglobulins. A study by Shibahara et al. in 275 infertile men reported the following isotype-stratified incidence rates: $2.5 \%$ for IgG, $1.8 \%$ for IgA and $0.4 \%$ for IgM [23]. Note that IgD and IgE isotypes are practically nonexistent in seminal fluid [24]. Compared to Shibahara et al. [23], we found a lower incidence rates in the retrospective study but similar values in 
the prospective study (with an increase in IgA-class antisperm antibody). The presence of immunoglobulins bound to different sections of spermatozoa has numerous repercussions on fertility. Studies have demonstrated negative effects on sperm-cervical mucus interaction, sperm mobility, acrosome reaction, sperm binding to the zonapellucida, and sperm-egg fusion [3] [5] [6] [25] [26]. Recent research also reports increased DNA fragmentation and an interrelation between oxidative stress and antisperm antibody levels [27]. These negative repercussions on fertility appear to be linked to the immunoglobulin isotype and where it binds to the surface of the sperm. IgA, which is thought to originate locally, shows stronger negative effects on fertility than the other isotypes [28]. When the IgA is bound to the sperm head, penetration of the zonapellucida is visibly diminished. This decrease could be explained by an interaction between the autoantibodies and free cholesterol fraction in the membranes of the capacitated spermatozoa, thereby preventing the membrane fluidity changes needed to orchestrate putative zona-binding and fusion to the egg [3]. Other mechanisms have also been posited, such as (non) specific blocking of water channel proteins (chiefly aquaporin water channels) [29]. When the IgA is bound to the tail, there is a risk that normal sperm penetration into the cervical mucus may be compromised as sperm start to show "shaky" motion [16] [24] [26] [30]. Compared to IgA, the other antibody isotypes G and $M$ have less damaging effect on fertility, even though IgG and IgM bound to the tail may drastically reduce the progressive motility of the spermatozoa [31]. Finally, in medically-assisted reproduction, antisperm autoantibodies are thought to be responsible for early abnormal cleavage and repeated failures in IVF [4] [19] [32]. In males, then, the relationship between sperm antibodies and immunological subfertility is complex to grasp. There is effectively an interplay of 3 components, each co-embedded to varying degrees, to factor in: 1) substantial heterogeneity in human sperm antigens, 2) the existence of different autoantibody classes (where IgA may be stronger drivers of subfertility) and 3) which part(s) of the spermatozoa anatomy theantibodies are bound to [23]. When coverslipping an ejaculate after liquefaction for 1 hour at $37^{\circ} \mathrm{C}$, the big two signs pointing to antisperm autoimmunity are: presence of sperm agglutinates (clumps of live spermatozoa) in the sample (Figure 1) and asthenozoospermia (reduced number of motile forms) [7] [8] [9] [18]. However, both criteria remain uneasy to appreciate. Even for an experienced semen tester, it is no easy task to distinguish aggregates (clumps of dead spermatozoa) from agglutinates [9]. Furthermore, background asthenozoospermia may curtail or even rule out any attempt to directly screen for antisperm antibodies simply by reducing the number of motile forms available (as immunobeads can bind nonspecifically to immotile spermatozoa). Finally, the fact that human semen is so inherently heterogeneous-even after a careful homogenization work-up-warrants extra caution when interpreting the semen analysis results, as there is always a chance that the tester may have missed a dense cluster of sperm agglutinates. In terms demographics and semen analysis results, both the retrospective dataset and prospective dataset populations showed a satisfactory level of sample homogeneity demonstrated zero recruitment bias. Furthermore, both studies used exactly the same 


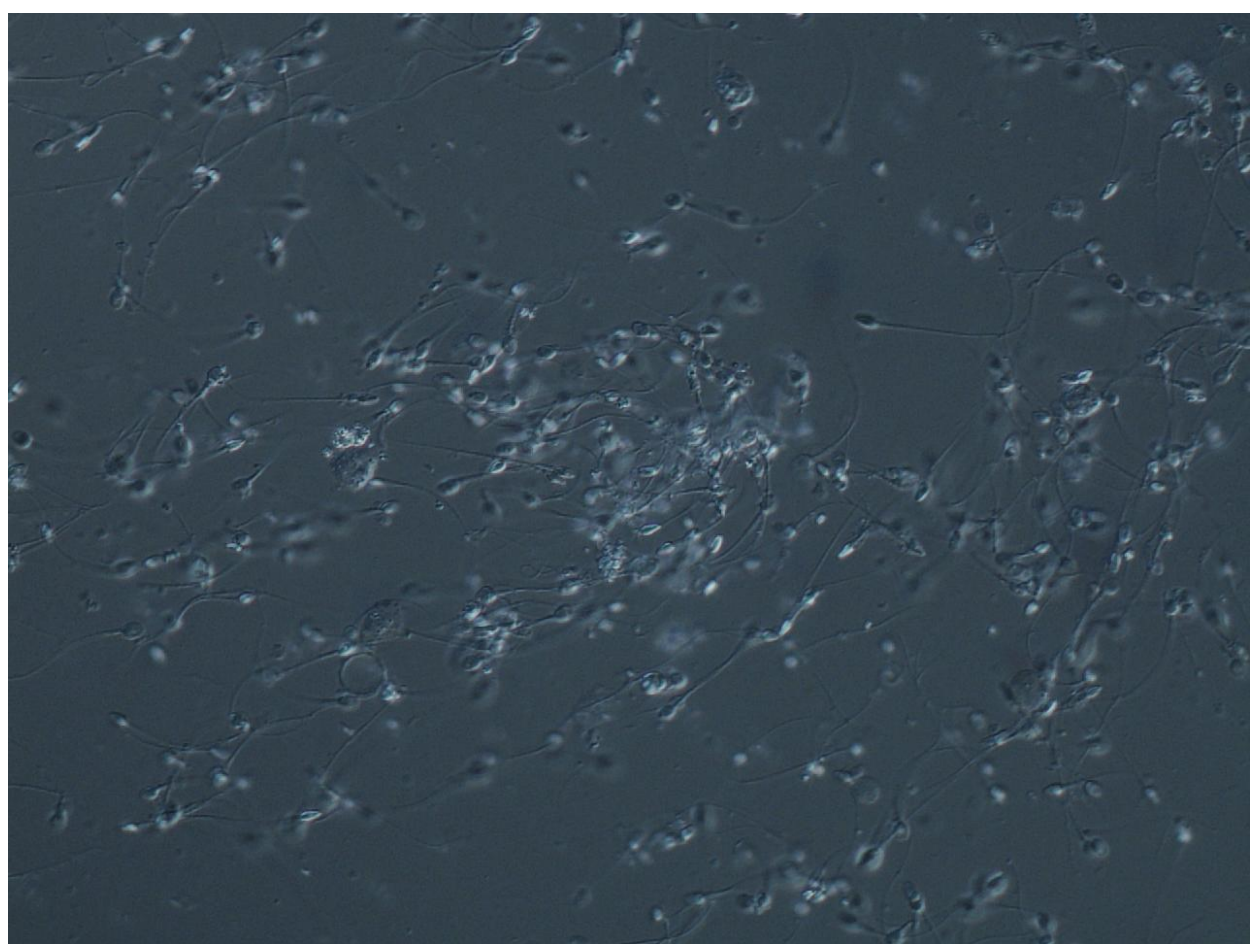

Figure 1. A fine spontaneous agglutinate in a fresh sperm (magnification 400x, interference contrast).

sperm analysis and direct antisperm antibody screening, thus ruling out any biases liable to skew the results. The significantly higher number of patients presenting spontaneous agglutinates in ejaculates in the prospective study compared to the retrospective study should be interpreted with caution, as we cannot rule out that semen testers who are aware of the study taking place may have unintentionally overestimated their spontaneous agglutinate readings. If we apply the percentage results for direct MAR-positives in the prospective sample $(7.88 \%)$ to the number of patients in the retrospective sample, then we can deduce that over the course of the 10-year period running from 1 April 2004 to 31 March 2014, we were potentially responsible for non-demonstration of antisperm autoimmunity in 146 patients. These putative 146 patients would stratify into a "virtual" count of 22 IgG-positive patients, 85 IgA-positive patients, and 39 mixed-class IgG plus IgA autoimmunity patients. The significantly higher incidence of antisperm antibodies in the prospective-study population compared to the retrospective cohort very clearly indicates that we had systematically underestimated this autoimmune condition over the 2004-2014 period. Furthermore, over the course of this 10 -year-long period, it is possible that some semen testers may have failed to read the difference between aggregates and agglutinates, and consequently not triggered screening for antisperm antibodies. It is equally possible that certain patients may have been antisperm antibody-positive even though their semen is signless. This was effectively the case for 8 patients (32\%) in the prospective study that showed absolutely no indications pointing to presence of autoimmunity. Furthermore, even if it is rare to find IgM in semen, the fact that the lab did not run targeted IgM screening means that we may 
have missed this class of antisperm antibody entirely. Ultimately, the impacts of the systematic underestimation described earlier in this study are a delay in the couple's infertility investigation, an inability for the practitioner to put a name on the underlying cause of infertility, and therefore-inexorably-potential psychological repercussions for each side of the couple. In this context, relying solely on presence of spontaneous agglutinates as a trigger for direct sperm MAR test to screen for an immunological cause of infertility looks far from adequate. From a diagnostic standpoint, on top of screening for antisperm antibodies, the seminogram is combined with a post-coital test to evaluate how the sperm interacts with the cervical mucus and thus pick up any anomalies in the progressive motility of spermatozoa, such as shaky or zigzagging movement. Finally, looking at the medical treatment options for the couple, studies have demonstrated the effectiveness of intrauterine insemination, a relatively straightforward medically-assisted reproduction protocol, after first eluting sperm-bound antibodies from the seminal fluid [4] [16] [18] [26] [33]. In conclusion, direct MAR test antisperm antibody screening is simple, quick, and easy to implement. Even though this screening test cannot be used to predict the chances of spontaneous pregnancy [34], our study brings compelling arguments for including screening for autoimmunity routinely as part of the basic workup for male subfertility wherever practicable (i.e. when sperm parameter analysis shows a high enough sperm count and zero asthenozoospermia) by the direct MAR test.

\section{References}

[1] Rümke, P. (1954) The Presence of Sperm Antibodies in the Serum of Two Patients with Oligospermia. Vox Sang, 4, 135-140.

[2] Wilson, L. (1954) Sperm Agglutinins in Human Semen and Blood. Experimental Biology and Medicine, 85, 652-655. http://dx.doi.org/10.3181/00379727-85-20982

[3] Calamera, J.C., Doncel, G.F., Brugo-Olmedo, S., Sayago, A. and Acosta, A.A. (2002) Male Antisperm Antibodies: Association with Modified Sperm Stress Test and Lipid Peroxidation. Andrologia, 34, 63-68. http://dx.doi.org/10.1046/j.0303-4569.2001.00467.x

[4] Tuech, J. (2012) Antisperm Antibodies: Screening and Application in 2011, from Male Infertility Checkup to Immunocontraceptive Vaccine. Andrologie, 22, 20-28.

[5] Bohring, C., Krause, E., Habermann, B. and Krause, W. (2001) Isolation and Identification of sperm Membrane Antigens Recognized by Antisperm Antibodies, and Their Possible Role in Immunological Infertility Disease. Molecular Human Reproduction, 7, 113-118. http://dx.doi.org/10.1093/molehr/7.2.113

[6] Kamieniczna, M., Domagala, A. and Kurpisz, M. (2003) The Frequency of Antisperm Antibodies in Infertile Couples-A Polish Pilot Study. Medical Science Monitor, 9, CR194-201.

[7] Phadke, A.M. and Padukone, K. (1964) Presence and Significance of Autoantibodies against Spermatozoa in the Blood of Men with Obstructed vas Deferens. Journal of Reproduction and Fertility, 7, 163-170. http://dx.doi.org/10.1530/jrf.0.0070163

[8] Rümke, P. (1974) The Origin of Immunoglobulinsin Semen. Clinical \& Experimental Immunology, 17, 287-297.

[9] Comhaire, F.H., Hinting, A., Vermeulen, L., Schoonjans, F. and Goethals, I. (1987) Evaluation of the Direct and Indirect Mixed Antiglobulin Reaction with Latex Particles for the 
Diagnosis of Immunological Infertility. International Journal of Andrology, 11, 37-44. http://dx.doi.org/10.1111/j.1365-2605.1988.tb01214.x

[10] David, G., Bisson, J.P., Czyglik, F., Jouannet, P. and Gernigon, C. (1975) Anomalies morphologiques du spermatozoïde humain. I. Proposition pour un système de classification. Journal de Gynécologie Obstétrique et Biologie de la Reproduction, 4, 17-36.

[11] WHO (1999) WHO Laboratory Manual for the Examination of Human Semen and Sperm-Cervical Mucus Interaction. 4th Edition, Cambridge University Press, Cambridge.

[12] WHO (2010) WHO Laboratory Manual for the Examination and Processing of Human Semen. 5th Edition, Cambridge University Press, Cambridge.

[13] Laudat, A., Lecourbe, K., Joyeux, C. and Burc-Struxiano, L. (2012) Corrélations croisées entre les pourcentages de formes typiques d'acrosomes malformés et l'index d'anomalies multiples : de potentiels indicateurs qualité? Annales de Biologie Clinique, 70, 105-108.

[14] Shulman, S., Zappi, E., Ahmed, U. and Davis, J.E. (1972) Immunologic Consequences of Vasectomy. Contraception, 5, 269-278. http://dx.doi.org/10.1016/0010-7824(72)90066-2

[15] Golomb, J., Vardinon, N., Homonnai, Z.T., Braf, Z. and Yust, I. (1986) Demonstration of Antispermatozoal Antibodies in Varicocele-Related Infertility with an Enzyme-Linked Immunosorbent Assay (ELISA). Fertility and Sterility, 45, 397-402. http://dx.doi.org/10.1016/S0015-0282(16)49224-1

[16] De Almeida, M. (1989) Immunologie et Hypofertilités Masculines. Revue Française de Gynécologie et d' Obstétrique, 84, 112-118.

[17] Siösteen, A., Steen, Y., Forssman, L. and Sullivan, L. (1993) Auto-Immunity to Spermatozoa and Quality of Semen in Men with Spinal Cord Injury. International Journal of Fertility, 38, 117-122.

[18] Francavilla, F., Romano, R., Santucci, R., La Verghetta, G., D’Abrizio, P. and Francavilla, S. (1999) Naturally-Occuring Antisperm Antibodies in Men: Interference with Fertility and Implications for Treatment. Frontiers in Bioscience, 4, e9-e25.

[19] Lee, R., Goldstein, M., Ullery, B.W., Ehrlich, J., Soares, M., Razzano, R.A., Herman, M.P., Callahan M.A., Li, P.S., Schlegel, P.N. and Witkin, S.S. (2009) Value of Serum Antisperm Antibodies in Diagnosing Obstructive Azoospermia. Journal of Urology, 181, 264-269. http://dx.doi.org/10.1016/j.juro.2008.09.004

[20] Mathur, S., Genco, P.V., Williamson, H.O., Koopman, W.R., Rust, P.F. and Fudenberg, H.H. (1983) Association of Human Leukocyte Antigens B7 and BW35 with Sperm Antibodies. Fertility and Sterility, 39, 397-398.

[21] Hjort, T., Husted, S. and Linnet-Jepsen, P. (1974) The Effect of Testis Biopsy on Autosensitization against Spermatozoal Antigens. Clinical and Experimental Immunology, 18, 201 212.

[22] Dörr, H., Bohring, C. and Krause, W. (2005) Are Antisperm Antibodies Indeed Sperm Specific? Andrologia, 37, 185-187. http://dx.doi.org/10.1111/j.1439-0272.2005.00675.x

[23] Shibahara, H., Tsunoda, T., Taneichi, A., Hirano, Y., Ohno, A., Takamizawa, S., Yamaguchi, C., Tsunoda, H. and Sato, I. (2002) Diversity of Antisperm Antibodies Bound to Sperm Surface in Male Immunological Infertility. American Journal of Reproductive Immunology, 47, 146-150. http://dx.doi.org/10.1034/j.1600-0897.2002.10059.x

[24] Friberg, J. (1980) Immunoglobulin Concentration in Serum and Seminal Fluid from Men with and without Sperm-Agglutinating Antibodies. American Journal of Obstetrics and Gynecology, 136, 671-675. http://dx.doi.org/10.1016/0002-9378(80)91022-4

[25] Kremer, J. and Jager, S. (1992) The Significance of Antisperm Antibodies for Sperm-Cervical Mucus Interaction. Human Reproduction, 7, 781-784. 
[26] Alexander, N.J. (1989) Natural and Induced Immunological Infertility. Current Opinion in Immunology, 1, 1125-1130. http://dx.doi.org/10.1016/0952-7915(89)90003-4

[27] Bozhedomov, V.A., Nikolaeva, M.A., Ushakova, I.V., Lipatova, N.A., Bozhedomova, G.E. and Sukhikh, G.T. (2015) Functional Deficit of Sperm and Fertility Impairment in Men with Antisperm Antibodies. Journal of Reproductive Immunology, 112, 95-101. http://dx.doi.org/10.1016/j.jri.2015.08.002

[28] Cui, D., Han, G., Shang, Y., Liu, C., Xia, L., Li, L. and Yi, S. (2015) Antisperm Antibodies in Infertile Men and Their Effect on Semen Parameters: A Systematic Review and MetaAnalysis. Clinica Chimica Acta, 444, 29-36. http://dx.doi.org/10.1016/j.cca.2015.01.033

[29] Rossato, M., Galeazzi, C., Ferigo, M. and Foresta, C. (2004) Antisperm Antibodies Modify Plasma Membrane Functional Integrity and Inhibit Osmosensitive Calcium Influx in $\mathrm{Hu}-$ man Sperm. Human Reproduction, 19, 1816-1820.

http://dx.doi.org/10.1093/humrep/deh317

[30] Kremer, J. and Jager, S. (1976) The Sperm-Cervical Mucus Contact Test: A Preliminary Report. Fertility and Sterility, 27, 335-340. http://dx.doi.org/10.1016/S0015-0282(16)41726-7

[31] Bronson, R.A., Cooper, G.W. and Rosenfeld, D.L. (1982) Correlation between Regional Specificity of Antisperm Antibodies to the Spermatozoan Surface and Complement-Mediated Sperm Immobilization. American Journal of Reproductive Immunology, 2, 222-224. http://dx.doi.org/10.1111/j.1600-0897.1982.tb00170.x

[32] Naz, R.H. (1992) Effects of Antisperm Antibodies on Early Cleavage of Fertilized Ova. Biology of Reproduction, 46, 130-139. http://dx.doi.org/10.1095/biolreprod46.1.130

[33] Kutteh, W.H., Byrd, W., Blankenship, L., Kutteh, C.C. and Carr, B.R. (1996) Cervical Mucus Anti-Sperm Antibodies: Treatment with Intrauterine Insemination. American Journal of Reproductive Immunology, 35, 429-433. http://dx.doi.org/10.1111/j.1600-0897.1996.tb00505.x

[34] Leushuis, E., van der Steeg, J.W., Steures, P., Repping, S., Schöls, W., van der Veen, F., Mol, B.W. and Hompes, P.G. (2009) Immunoglobulin G Antisperm Antibodies and Prediction of Spontaneous Pregnancy. Fertility and Sterility, 92, 1659-1665. http://dx.doi.org/10.1016/j.fertnstert.2008.08.082

\section{Submit or recommend next manuscript to OALib Journal and we will provide best} service for you:

- Publication frequency: Monthly

- 9 subject areas of science, technology and medicine

- Fair and rigorous peer-review system

- Fast publication process

- Article promotion in various social networking sites (LinkedIn, Facebook, Twitter, etc.)

- Maximum dissemination of your research work

Submit Your Paper Online: Click Here to Submit

Or Contact service@oalib.com 